\section{Suicide in farmers}

\author{
ASLÖG MALMBERG, SUE SIMKIN and KEITH HAWTON
}

\begin{abstract}
"Stressed, misunderstood and lonely", runs a fairly typical newspaper headline linking suicide in farmers to financial problems, social isolation and low status (The Independent, 10 February 1996). Farmers are one of the occupational groups at greatest risk of suicide in England and Wales (Kelly \& Bunting, 1998), but apart from individual case reports in the media there has been very little research into the reasons for this. Most of the studies on farming suicide are from North America (e.g. Gunderson et al, 1993), stimulated by the farming crisis in the $1980 \mathrm{~s}$, but it seems unlikely that their findings can be generalised to the current situation in the UK. To remedy this lack of information the Department of Health commissioned a research programme into suicide in farmers which has recently been completed (Hawton et al, $1998 b$ ); it included a psychological autopsy study which is described briefly here.
\end{abstract}

\section{PSYCHOLOGICAL AUTOPSY STUDY}

In the psychological autopsy approach, information about individuals who have committed suicide is gathered from inquest records, medical notes and, where possible, an interview with a relative or friend to try to understand the reasons for the death (Shneidman, 1981). The sample for this study included all farm owners, tenants and managers who had died between October 1991 and December 1993 and received a verdict of suicide or an open verdict ('undetermined cause') at a coroner's inquest. Death certificates supplied by the Office for National Statistics (ONS) gave basic demographic information and the cause of death. The final sample consisted of 84 farmers: 71 suicide verdicts $(85 \%)$ and 13 open verdicts $(15 \%)$. One farmer was excluded as his death was almost certainly an accident. We achieved a lower retrieval rate for information from coroners $(85 \%)$, general practitioners (GPs) $(86 \%)$ and relative interviews $(28 / 53,53 \%)$ than some other studies (Foster et al, 1997). This was probably due in part to some delay after the deaths, caused by using the ONS as a source of data, which was the only practical option. The quality and quantity of data varied between subjects, a wellknown methodological problem in psychological autopsy studies (Hawton et al, $1998 a$ ). The frequency of some variables is therefore almost certainly underestimated, and the denominator varies between variables.

A limited control group for some variables was provided by 500 living farmers who answered a postal questionnaire ( $51 \%$ response rate) about sources of stress in farming (Hawton et al, 1998b).

\section{Demographic information and type of farm}

Once all the information was reviewed it was clear that only $58(69 \%)$ of the sample were actually working in farming at the time of their death, and most of the data discussed here relate to them. The remainder had retired or stopped working because of ill health several years before their deaths. This has obvious implications for the interpretation of official suicide statistics and the possible relevant risk factors.

Livestock farmers working on small farms have been more exposed to market fluctuations over the past few years than arable farmers on larger farms and might have been expected to be over-represented compared with national figures (Ministry of Agriculture, Fisheries and Food et al, 1994). However, this was not the case, and with the exception of pig farming, no one type of farming activity was more common among the working farmers than among those answering the stress survey $(8 / 47,17 \%$ v. $36 / 500,7 \%)$. Pig farming is capital intensive and unsupported by subsidy.

\section{Problems in the year before death}

Table 1 summarises the problems faced by working and retired farmers in the year before death. No information regarding problems was available on two of the suicides, six farmers had had problems with their mental or physical health but no difficulties in any other areas of their lives, and two farmers appeared to have had no problems at all and had committed suicide unexpectedly. All other farmers had had problems in several areas of their lives, with the most common combination being mental health, work, finances and family or partner. Most suicides were the end point of a series of difficulties developing over time rather than a response to an acute crisis, and in this respect farmers are no different from other people who commit suicide. The nature of farming, particularly when the farm is a family business, means that many problems are inevitably interconnected, and this may be more important for farmers than those in other occupations. In this study disputes between father and son often had serious effect on the running of the farm, and divorce could mean having to sell the farm if it was owned jointly by both spouses.

\section{Mental illness}

The most frequent single problem and the one which was most often judged to be important in the death was mental illness. Thirty-nine farmers $(46 \%)$ were definitely

Table I Problems faced by working and retired farmers in the year before death

\begin{tabular}{lcc}
\hline Problem & $\begin{array}{c}\text { Working sample } \\
(n=56)\end{array}$ & $\begin{array}{c}\text { Retired sample } \\
(n=26)\end{array}$ \\
\hline $\begin{array}{l}\text { Mental } \\
\text { health }\end{array}$ & $39(70 \%)$ & $17(65 \%)$ \\
Occupational & $29(52 \%)$ & $7(27 \%)$ \\
Relationship & $23(41 \%)$ & $6(23 \%)$ \\
Physical & $21(38 \%)$ & $22(85 \%)$ \\
health & & $1(4 \%)$ \\
Family & $16(29 \%)$ & $2(8 \%)$ \\
Financial & $15(27 \%)$ & $2(8 \%)$ \\
Bereavement & $13(23 \%)$ & 0 \\
Legal & $7(13 \%)$ & $1(4 \%)$ \\
Alcohol & $5(9 \%)$ & $2(8 \%)$ \\
Isolation & $2(4 \%)$ & $1(4 \%)$ \\
Housing & $1(2 \%)$ & 0 \\
Sexual & $1(2 \%)$ & $4(15 \%)$ \\
Other & $1(2 \%)$ & \\
\hline & & \\
\hline
\end{tabular}


and $19(23 \%)$ were probably suffering from a mental illness at or near the time of death (ICD-10; World Health Organization, 1993). These rates are not as high as in community-based studies of suicide (e.g. Foster et al, 1997) and are probably an underestimate because of the limited information available on some subjects. The pattern of diagnosis is similar to that of population-based studies, with depressive disorder the most frequent diagnosis, occurring in $\mathbf{5 4}$ farmers. There were low rates of alcohol dependence (six farmers) and no cases of schizophrenia, probably reflecting the difficulty of running a successful farm, as most of the subjects had been doing, with a chronic mental health problem. There was also a lower rate of previous suicide attempts (11 farmers, $14 \%$ ) than in other studies (Foster et al, 1997), which may reflect a farmer's wish to take decisive action and the availability of means of committing suicide. Suicide threats should be taken particularly seriously in farmers: where interview information was available, $46 \%$ had made a clear suicidal communication within three months of death.

Farmers have a reputation for being stoical in the face of health problems and reluctant to seek help. Although the farmers in this study were just as likely to have consulted their GP as subjects in other studies of suicide $(46 \%$ within one month, $67 \%$ within three months; see Pirkis \& Burgess (1998) for comparison figures), many of these consultations represented missed opportunities for the detection and treatment of depression. Complaints of tiredness and insomnia were often taken at face value and treated symptomatically; this seemed to arise from a lack of knowledge and reluctance to consider and discuss emotional problems by the farmer and doctor. Several family members commented that they had been unaware of the signs and symptoms of depression and its treatability. Only 19 $(37 \%)$ of the 52 subjects who were depressed (excluding two with bipolar disorder) were being treated with antidepressants, and seven had been prescribed an inadequate dose (less than $100 \mathrm{mg}$ equivalent of a tricyclic).

\section{Occupational problems}

Studies of stress in farming from the UK and abroad (McGregor et al, 1995) have consistently identified financial pressures, concern over farming policy and administration, unpredictable weather conditions and time pressure as important sources of stress for farmers in general. Financial and workrelated problems affected the majority of working farmers $(64 \%)$ in this study, and financial problems in particular were seen as important factors in the suicide. For seven farmers there was an imminent danger of the farm being lost. The reasons why farmers had got into financial problems varied and included unexpected market fluctuations, failed attempts to expand the farm involving capital outlay, bad luck and poor planning. Some relatives commented during interviews that a more sympathetic attitude from banks would have been helpful. Unhappiness about facing retirement was the next most common occupational problem. This was a difficult watershed involving a loss of role and possibly of accommodation, and it had often been approached without adequate planning. Other occupational problems included unhappiness about being in farming, refusal of important planning applications, disputes with other family members working on the farm, and, less frequently, working long hours, difficulties with paperwork, the threat of prosecution under health and safety legislation, difficulties between partners running the farm and disputes with landlords and neighbours. Several relatives also complained about the burden of new legislation and paperwork.

The possible detrimental effects of organophosphates, particularly sheep dip, have been widely reported (e.g. Davies, 1995). However, this was rarely commented on in inquest records and GP notes, and relatives often did not know exactly which chemicals had been used on the farm. Studies of a different design, such as case-control and longitudinal studies of unselected populations, could address this question properly. Sheep farmers were not over-represented among the suicides.

\section{Physical illness}

Physical illness is an important risk factor for suicide in the general population (Harris \& Barraclough, 1994) and in farmers (Pentinnen, 1995) and was a significant problem for many farmers in this study. Taking time off to rest and get treatment is difficult for most farmers and the financial implications of being too ill to work are obvious.

\section{Relationship problems}

Family and relationship problems were common but were less likely than financial difficulties to be seen as a major influence on the suicide. However, they undoubtedly raised the background level of stress and cut off sources of support.

\section{Social support}

In keeping with findings from stress surveys (McGregor et al, 1995), social isolation in the sense of not seeing many people during the course of the day did not emerge as an important problem. Most of the farmers in the study did not lack casual social contacts, but, compared with the farmers who answered the stress survey, significantly more of the farmers who died lived alone $(18 \%$ v. $8 \%)$, lacked close friends ( $31 \% v .5 \%)$ and, especially, had no confidant $(52 \% \nu$. $8 \%$ ). Part of farmers' reticence to confide in others outside the family may be to do with concerns about confidentiality in small communities where their business standing could be affected by rumours of problems. Whether any of these farmers would have used the support groups and telephone helplines which have been established in some counties is not clear, and audit of these initiatives is important.

\section{Method of suicide}

Work on survivors of serious suicide attempts suggests that many suicides are probably impulsive, at least in terms of timing, and that availability of a lethal method is important (O'Donnell et al, 1996). The most common methods overall in both the retired and working groups were hanging $(43 \%)$, shooting $(27 \%)$, drowning $(11 \%)$ and car exhaust poisoning $(10 \%)$. The high rates of death from shooting, $27 \%$ in this sample compared with $4.2 \%$ of male suicide deaths in the general population in 1993 (Office for National Statistics, 1997), reflect the wide ownership of guns in the farming community. However, farmers' wives rarely use firearms in suicide deaths (Kelly et al, 1995), and a further factor such as familiarity with use or being accustomed to killing sick animals may also be important. A particularly disturbing finding was that four of the interview subjects had either threatened suicide by shooting before their death, or caused their family to be concerned for their safety and to take unsuccessful steps, including involving the police, to prevent access to the gun.

\section{PREVENTION}

Although targeting high-risk groups for suicide prevention is controversial (Lewis et al, 
1997), the large number of deaths among farmers (526 between 1979 and 1990; Charlton et al, 1993) suggests that prevention programmes are important. Farmers who kill themselves are similar in many ways to other people who do so, but have the additional burden of running a business subject to changing agricultural policy and working in an environment which makes it difficult to admit to problems and seek appropriate help. The risk of suicide is not confined to any particular sector of the farming community. The key explanatory variables in this study were the presence of mental illness, low rates of treatment, the lack of a close confiding relationship, work and financial problems and the availability of firearms, suggesting a range of possible interventions - medical, social and political - which could be targeted specifically at farming communities.

Many farmers and their families belong to farming organisations which could act as coordinators of prevention programmes. Several, including the Samaritans and the National Farmers' Union (NFU), have already been active in this area and have focused on providing social support, counselling and practical help for farmers. In 1987, the Samaritans launched a 'Rural Initiative' to raise their profile in rural communities, and they later launched various 'County Rural Initiatives' with the same purpose. The NFU coordinates the Rural Stress Information Network, which links and supports local county groups. Other organisations including the Citizens' Advice Bureaux, the mental health charity Mind and the Farming and Rural Conservation Agency (formerly ADAS) have also been involved (for further details see Hawton et al, $1998 b$ ), and informal support groups and telephone helplines have been set up by individuals with varying take-up and success. An increasing number of people from rural areas are calling telephone helplines (The Samaritans, 1997) but it is not clear at the moment what impact they will have on suicide rates.

General practitioners and psychiatrists working in rural areas need to be reminded again of somatic presentations of depressive illness and encouraged to prescribe antidepressants at adequate doses when appropriate. Routine health checks focusing on physical problems may provide an opportunity to assess and treat depression. Information about the signs and symptoms of stress and depression could be disseminated through agricultural colleges, the Women's

ASLÖG MALMBERG, MRCPsych, SUE SIMKIN, BA, KEITH HAWTON, DM, University Department of Psychiatry. Warneford Hospital, Oxford

Correspondence: Aslög Malmberg. PO Box 650528, Benmore 2010, Johannesburg. Republic of South Africa

(First received 10 September 1998, final revision I February 1999, accepted 2 March 1999)

Institute and other rural organisations, and the farming media. When mental illness has been identified an assertive outreach approach to treatment with domiciliary visits by the GP, psychiatrist or community psychiatric nurse will often be essential. Confidentiality is particularly important.

Addressing work and financial problems is a difficult area, but policy-makers should at least be aware of the potential financial impact of new legislation. Retirement schemes such as those available in other European Union countries have previously been rejected for financial reasons, but may need to be reassessed. Information about planning for retirement needs to be reinforced by farming organisations and agricultural colleges. Although many of the initial problems with paperwork arising from Britain's membership of the European Union have now been overcome, there is still a need to monitor the forms associated with new legislation and provide assistance with their completion. Although there has been a decrease in the proportion of farmers who use firearms to kill themselves in the past decade (Hawton et al, 1998b), they are still a common method of suicide among farmers. General practitioners, other clinicians and police should be more proactive in removing guns and, if necessary, revoking gun licences if there is evidence of suicidal behaviour or abnormal mental states.

\section{ACKNOWLEDGEMENTS}

The study was supported by a grant from the Department of Health. K.H. and S.S. were also supported by the Oxford and Anglia NHS Executive Research and Development Fund. We also thank the National Farmers' Union and The Samaritans for their advice. and all the coroners, general practitioners and, most importantly, relatives who participated in the study.

\section{REFERENCES}

Chartton, J., Kelly, S., Dunnell, K., et al (1993) Suicide deaths in England and Wales: trends in factors associated with suicide deaths. Population Trends, $7 \mathbf{7}$. $34-42$.
Davies, D. R. (1995) Organophosphates, affective disorder and suicide. Journol of Nutritional and Environmental Medicine, 5, 367-374.

Foster, T., Gillespie, K. \& McClelland, R. (1997) Mental disorders and suicide in Northern Ireland. British journal of Psychiatry. 170, 447-452

Gunderson, P., Donner, D., Nashold, R., et al (1993) The epidemiology of suicide among farmer residents or workers in five nor th-central states, 1980-1988. American journal of Preventive Medicine, 9. 26-32.

Harris, E. C. Barraclough, B. M. (1994) Suicide as an outcome for medical disorders. Medicine, 73. 281-296.

Hawtion, K., Appleby, L., Platt, S., ot ol (19980) The psychological autopsy approach to studying suicide: a review of methodological issues. Journal of Affective Disorders, 50, 269-276

_, Simkin, S., Malmberg, A., et al (1998b) Suicide and Stress in Farmers. London: The Stationery Office.

Kelly, S., Chartton, J. \& Jenkins, R. (1995) Suicide deaths in England and Wales, 1982-92: the contribution of occupation and geography. Population Trends, 80. 16-25.

- Bunting, J. (1998) Trends in suicide in England and Wales, 1982-96. Population Trends, 92, 29-41.

Lewis, G., Hawton, K. \& Jones, P. (1997) Strategies for preventing suicide. British journal of Psychiatry. I7I. $351-354$.

McGregor, M., Willcock, J. \& Deary, I. (1995) Farmer stress. Form Monogement, 9, 57-65.

Ministry of Agriculture, Fisheries and Food, The Scottish Office Agriculture and Ftaheries Department, Department of Agriculture for Northern Ireland, et ol (1994) The Digest of Agricultural Census Statistics. United Kingdom 1993. London: HMSO.

O'Donnell, 1., Farmer, R. \& Catalan, J. (1996) Explaining suicide: the views of survivors of serious suicide attempts. British journal of Psychiatry. 168. 780-786.

Ofice for National Statistics (1997) The Twentieth Century Mortality Files (CD-ROM). London: Office for National Statistics.

Pentinnen, J. (1995) Back pain and the risk of suicide among Finnish farmers. American journal of Public Health, 85, 1452-1453.

Pirkis, J. \& Burgess, P. (1998) Suicide and recency of health care contacts. A systematic review. British journol of Psychiotry, 173, 462-474.

Shneidman, E. S. (1981) The psychological autopsy. Suicide and Life Threatening Behavior, II. 325-340.

The Samaritans (1997) County Rural Initiotives Reaching out to Rural People. Slough: The Samaritans.

World Health Organization (1993)

The ICD-10 Classification of Mental and Behavioural Disorders. Diognostic Criterio for Research. Geneva: WHO. 